\title{
CIDADANIA AMBIENTAL E PARTICIPAÇÃO POPULAR: EFETIVIDADE DA LEGISLAÇÃO AMBIENTAL EM UM PARQUE DE ENERGIA SOLAR NO PIAUÍ
}

\author{
ENVIRONMENTAL CITIZENSHIP AND POPULAR PARTICIPATION: EFFECTIVENESS OF \\ ENVIRONMENTAL LEGISLATION IN A SOLAR ENERGY PARK IN PIAUÍ
}

\author{
Ana Keuly Luz Bezerr ${ }^{1}$ \\ Afonso Feitosa Reis Neto ${ }^{2}$ \\ Maristela Oliveira de Andrade ${ }^{3}$
}

\section{RESUMO}

O setor energético produz impactos ambientais, desde a captura dos recursos para a geração de energia até o consumo final. Assim, é importante mitigar os impactos socioambientais decorrentes desta atividade, que estão presentes inclusive na utilização de fontes alternativas, como a energia solar, através de uma melhor regulamentação da atividade e com a participação popular. Nesse sentido, o presente artigo tem como objetivo analisar o fenômeno da participação popular no

\footnotetext{
${ }^{1}$ Docente do eixo tecnológico de Gestão e Negócios do Instituto Federal do Piauí - Campus Avançado Dirceu Arcoverde. Doutora e Mestre em Desenvolvimento e Meio Ambiente pela UFPI. Graduada em Administração e Direito. Orientadora do Programa de Mestrado em Políticas Públicas da Universidade Federal do Piauí. Instituto Federal do Piauí, Instituto Federal do Piauí - Campus Avançado Dirceu Arcoverde - Brasil. ORCID Id: http://orcid.org/0000-0002-6234-2474 Lattes: http://lattes.cnpq.br/9779727227180112 E-mail: prof.anakeuly@gmail.com

2 Doutor e Mestre em Desenvolvimento e Meio Ambiente pela Universidade Federal de Pernambuco (PRODEMA/UFPE). Graduado em Direito pela Universidade Federal de Pernambuco (UFPE). Graduado com láurea em Gestão Ambiental pelo Instituto Federal de Educação, Ciência e Tecnologia de Pernambuco (IFPE). Advogado (OAB/PE). Docente do Instituto Federal de Educação, Ciência e Tecnologia do Piauí (IFPI) - Área: Gestão Ambiental. É um dos Editores-Chefes e cofundador da Revista Brasileira de Meio Ambiente - RVBMA (ISSN: 25954431). Líder do Grupo de Pesquisa/CNPQ - Laboratório Interdisciplinar Sociedade, Ambiente e Direito (LISA-D). Estágio pós-doutoral na Universidade Federal do Piauí (UFPI). Possui como principais temáticas de estudo: Direito Ambiental, Direito Ecológico, Gestão Ambiental e Ética Ambiental. Instituto Federal do Piauí - Campus Corrente - Brasil. ORCID Id: http://orcid.org/0000-0002-7333-4736 Lattes: http://lattes.cnpq.br/7382862676934597 Email: afonso.reis@ifpi.edu.br

3 Possui graduação em Psicologia pela Universidade Católica de Pernambuco (1978), Especialização em Antropologia Cultural (UFPE) (1984) e doutorado em Étude Latino-Americaine/ Anthropossociologie des Religions - Institut de Hautes Études de I'Amérique Latine - IHEAL, Université de Paris III (Sorbonne-Nouvelle) (1983). É Professora Titular aposentada da Universidade Federal da Paraíba, e atualmente atua como professora voluntária nos Programas de Pós-Graduação em Antropologia e em Desenvolvimento e Meio Ambiente. Criou o Grupo Interdisciplinar de Pesquisa em Cultura, Sociedade e Ambiente (2012) do qual é coordenadora adjunta. Atua principalmente nos seguintes temas: Território, populações tradicionais, desenvolvimento e meio ambiente, bem como no campo da religião e religiosidades, movimentos religiosos contemporâneos. Universidade Federal da Paraíba - Brasil. ORCID Id: http://orcid.org/0000-0001-7393-3977 Lattes: http://lattes.cnpq.br/7202471430678926 E-mail: andrademaristela@hotmail.com
} 
enfrentamento dos impactos socioambientais como exercício da cidadania ambiental, tomando como estudo de caso um movimento de moradores do entorno de um Parque Solar no Piauí. Nos procedimentos metodológicos utilizou-se a pesquisa qualitativa e descritiva, baseada na pesquisa bibliográfica e de campo. A pesquisa revelou que a atuação da população por meio de mobilização social, pode ser considerada como exercício da cidadania ambiental, uma vez que ao afirmar seu direito ao meio ambiente como direito fundamental, conseguiu alertar o Poder Público para os impactos socioambientais causados pelas obras do Parque Solar, possibilitando a efetividade da legislação ambiental.

Palavras-chaves: Cidadania. Impacto ambiental. Conflitos socioambientais. Energias renováveis.

\section{ABSTRACT}

The energy sector produces environmental impacts, from capturing resources for power generation to final consumption. Thus, it is important to mitigate the socio-environmental impacts resulting from this activity, which are present even in the use of alternative sources, such as solar energy, through better regulation of the activity and with popular participation. In this sense, this article aims to analyze the phenomenon of popular participation in addressing socio-environmental impacts as an exercise of environmental citizenship, taking as a case study a movement of residents around a Solar Park in Piauí. In the methodological procedures, qualitative and descriptive research was used, based on bibliographic and field research. The research revealed that the performance of the population through social mobilization, can be considered as an exercise of environmental citizenship, since by affirming their right to the environment as a fundamental right, they managed to alert the Public Power to the socio-environmental impacts caused by the works of the Solar Park, enabling the effectiveness of environmental legislation.

KEYWORDS: Citizenship. Environmental impact. Socioenvironmental conflicts. Renewable energy.

\section{INTRODUÇÃO}

O direito e a democracia precisam conviver com a contínua aceleração das mudanças na humanidade e no planeta juntamente com à intensificação dos ritmos de vida e trabalho. Embora a mudança faça parte da dinâmica dos sistemas complexos, a velocidade que hoje lhe impõem as ações humanas contrasta com a lentidão da evolução positivista do direito. A isto vem juntar-se o problema de que os objetivos desta mudança rápida e constante não estão necessariamente orientados para o 
bem comum e para o desenvolvimento sustentável. A mudança é algo desejável, mas torna-se preocupante quando se transforma em deterioração do mundo e da qualidade de vida de grande parte da humanidade.

A busca contínua por meios sustentáveis de geração energética ocorre por motivos econômicos (escassez de recursos fósseis) e ambientais (diminuição dos impactos ambientais). Nessa seara, as energias eólica e solar despontam como as principais sendo vistas com grande entusiasmo, principalmente no Nordeste brasileiro que historicamente sofre com problemas ligados à integração e distribuição na rede nacional. Todavia, os eixos de geração de energia no Brasil apresentam características ambientalmente insustentáveis e socialmente injustos que intensificam os conflitos socioambientais (ALVES; REIS NETO; PACHECO, 2019; PALHETA; NASCIMENTO; SILVA, 2017).

Os conflitos estão inseridos em um amplo leque de disputas (ACSELRAD, 2010) incluindo os movimentos em defesa e reapropriação da biodiversidade; disputas entre a preservação ambiental e a comercialização de recursos, bens e serviços ambientais; dissensos acerca dos mecanismos econômico-jurídicos e os direitos de apropriação da natureza por um pequeno grupo de atores em detrimento de grande parte da população. Esses aspectos tornam-se ainda mais evidentes quando analisadas as áreas/pessoas diretamente afetadas pelos empreendimentos energéticos.

A realidade dos fatos também faz questionar, se, numa perspectiva crítica, a implantação de projetos de geração de energia busca em verdade privatizar os benefícios para poucos e socializar os conflitos/problemas para grande parte da sociedade. O corpo social, em grande medida, além de não participar e não ser levado em consideração nos processos de tomada das decisões ambientais, têm os seus direitos de cidadania frequentemente negados (BAHIA, MELO, 2018).

O fundamento democrático se estrutura em bases institucionais rígidas, remetendo a justificação de sua organização à proteção da obrigação institucional de respeito à intangibilidade dos direitos fundamentais e ao conteúdo material da Constituição; essas dificuldades seriam solucionadas em termos objetivos de justificação, retirando-se o poder arbitrário que se pretenderia arrogar a maioria parlamentar, ou mesmo o povo, diretamente, em sua definição (ACKERMAN, 1991).

Assim, as crescentes reivindicações sociais por justiça ambiental são definidas pela constatação de que existe uma má distribuição dos bens e dos riscos ambientais nas sociedades contemporâneas, responsáveis por afetar e mesmo violar direitos das parcelas mais vulneráveis da população (ACSELRAD, 2010). O ponto fundamental do debate vem sendo a busca da superação das desigualdades impostas pelo processo de produção capitalista traduzidas pela concentração dos danos à natureza em grupos sociais economicamente mais frágeis. 
A situação ganha um maior agravante em virtude da fragilidade institucional/representativa destes grupos. Esse fato faz com que diversas barreiras apareçam e dificultem, por conseguinte, as modificações neste modelo socioeconômico, seja para que essas externalidades ambientais sejam distribuídas equitativamente, ou mesmo, eliminadas. Para tanto é fundamental que o sistema de direitos baseados na participação popular e no desenvolvimento sustentável sejam salvaguardados.

A existência da cidadania ambiental é um dos fundamentos para garantir a real efetividade da legislação ambiental (CHACÓN, 2019). Nesse sentido, o direito ao meio ambiente ecologicamente equilibrado é um direito fundamental de terceira geração, e como tal, deve ser resguardado e reivindicado por todos. Portanto, essas questões são conectadas à democracia e à participação, sendo imperioso garantir a transparência, a responsabilização e a participação nos procedimentos decisórios, possibilitando um envolvimento da sociedade nas decisões ambientais (BAHIA; MELO, 2018), inclusive no papel de fiscalização dos danos ambientais como direito potestativo.

A nova cidadania ambiental que se busca é mais abrangente e não está circunscrita espacialmente a determinado território ou ligada a um determinado povo oriundo da significação clássica de nação; ela tem como objetivo comum a proteção intercomunitária do bem difuso ambiental, fugindo dos elementos referidos da cidadania clássica (BAHIA; MELO, 2018). Contudo não há como negar que o Estado de hoje ainda atua de forma conservadora, precária, insuficiente e predatória, dando preferência à gestão econômica e negligenciando o exercício dessa responsabilidade compartilhada na preservação ambiental (BAHIA; MELO, 2018). Dessa forma, a formação do Estado de Direito Ambiental exige uma efetiva colaboração entre Estado e cidadão na gestão ambiental pública.

Esse quadro descrito pode ser visualizado no caso da instalação do Parque Solar no município de São Gonçalo do Amarante, Piauí. No ano de implantação, 2018, foi considerado o maior da América do Sul. A problemática do presente artigo reside na questão: Como aconteceu a participação popular nesse cenário do Parque Solar enquanto exercício da cidadania ambiental para efetivação da legislação ambiental?

A importância social do estudo reside na compreensão da participação popular como agente reivindicador da aplicação da legislação ambiental nas modificações realizadas pelo Parque Solar na dinâmica do município. Ademais, com o presente caso, será possível perceber o papel fundamental dos princípios do direito ambiental (a informação, participação e responsabilização) para cumprimento da proteção ambiental. 
Nesse sentido, o presente artigo tem como objetivo analisar o fenômeno da participação popular no enfrentamento dos impactos socioambientais como exercício da cidadania ambiental, tomando como estudo de caso um movimento de moradores do entorno de um Parque Solar no Piauí.

\section{MATERIAIS E MÉTODOS}

\section{1 Área de Estudo}

São Gonçalo do Gurgueia está localizado na microrregião do Alto Médio Gurguéia (Figura 1), compreendendo uma área de $1.233 \mathrm{~km}^{2}$, tendo como limites os municípios de Gilbués (localidade com intensa área de desertificação) e Barreiras do Piauí (parte do município faz parte do Parque Nacional das Nascentes do Rio Parnaíba) ao norte e ao sul com a municipalidade de Corrente (região com grande influência das atividades agropecuárias). O bioma predominante na região é o Cerrado (IBGE, 2019).

O município apresentou uma população de 2.825 habitantes no último censo (2010), tendo como população estimada, para 2019, 3.041 habitantes (IBGE, 2019). Alguns números merecem ser destacados para entender o contexto das modificações advindas com o Parque Solar na dinâmica social. $56,3 \%$ da população economicamente ativa recebe até $1 / 2$ salário mínimo. Outro percentual que chama atenção é que apenas 1,1\% dos habitantes possuem esgotamento sanitário (IBGE, 2019). Todos esses fatores refletem no Índice de Desenvolvimento Humano Municipal (IDHM) de 0,560 (IBGE, 2019).

Tais afirmações ajudam a compreender o que representa, sob o ponto de vista econômico, a chegada do empreendimento para região. Um grande contingente de pessoas (no pico das obras mais de 1.500 trabalhadores) de diversas regiões do Brasil, necessidade de criação de infraestrutura (alimentação, hospedagem, saúde, lazer) e os impactos territoriais inerentes a todas essas características (PALHETA; NASCIMENTO; SILVA, 2017). 
Figura 1 - Localização do Parque de Energia Solar em São Gonçalo do Gurgueia, Piauí.

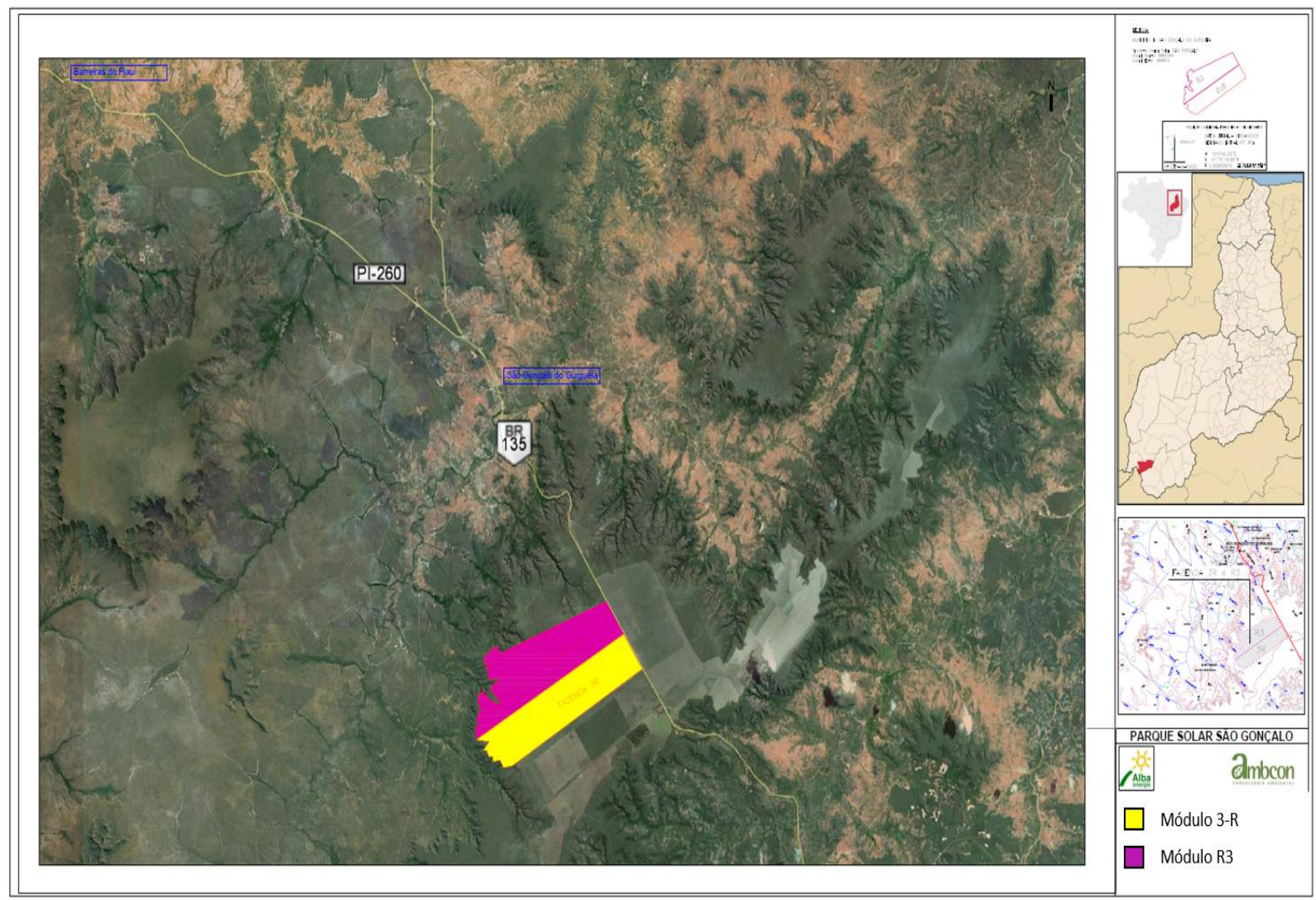

Fontes: EIA/RIMA Parque Solar (ALBA ENERGIA, 2017).

A planta solar começou a ser instalada no início de agosto de 2018, e a operação teve início em janeiro de 2020, para gerar $475 \mathrm{MW}$ de energia e envolveu um investimento de $\mathrm{R} \$ 1,4$ bilhão, podendo ser capaz de gerar mais de 1.200 GWh por ano (ALBA ENERGIA, 2017). Foi anunciada recentemente a expansão do Parque Solar para construção da expansão de $133 \mathrm{MW}$, na qual a empresa responsável está investindo cerca de $\mathrm{R} \$ 422$ milhões. Em pleno funcionamento a planta inteira (608 MW) será capaz de gerar mais de 1.500 GWh (ALBA ENERGIA, 2017). A usina localizada no Piauí é a primeira empresa no país que utiliza módulos solar bifacial responsáveis pela captura da energia de cada lado dos painéis para energia solar.

O projeto previa a implantação em uma área de cerca de 1.705 ha, sendo que a propriedade das Fazendas R3 e 3-R contêm, juntas, uma área total de cerca de 2.281 ha. De acordo com o EIA/RIMA do empreendimento, no momento da construção, era considerado o maior parque de geração de energia solar da América do Sul (ALBA ENERGIA, 2017). 


\subsection{Procedimentos Metodológicos}

A pesquisa bibliográfica foi realizada a partir dos principais diplomas legais que podem ser utilizados para fundamentar a discussão dos conceitos de cidadania ambiental e a participação social na gestão ambiental nos empreendimentos de grande impacto ambiental. Nesse sentido, as principais fontes de consulta foram: Constituição Federal de 1988, Lei Federal n. 6.938/1981, Lei Complementar 140/2011, Resolução CONAMA 01/86, CONAMA 09/87 e CONAMA 237/97. Além dessas, instruções normativas do IBAMA e do Ministério do Meio Ambiente, e a legislação estadual do Piauí, que, de alguma maneira, contribuem para a discussão da participação da população na gestão ambiental de obras de grande impacto.

Para tanto, além das referidas leis, foram feitos comentários sobre o Estudo de Impacto Ambiental (EIA) disponibilizado pela responsável do empreendimento em audiência pública ocorrida no ano de 2018. Ademais, também serviram de fontes para a pesquisa as notícias disponibilizadas na página oficial da Secretaria de Meio Ambiente e Recursos Hídricos do Estado de Piauí e dos portais jornalísticos locais do extremo sul piauiense que executaram uma intensa cobertura sobre a implantação do Parque Solar. Cabe destacar que essa fonte de informação se justifica pelo acesso desses portais no cotidiano das comunidades, bem como pela proximidade com os danos ambientais retratados. Esse contexto não seria possível com grandes portais de mídias.

Além da consulta às fontes bibliográficas, os autores tiveram a oportunidade de participar, como observadores, de uma manifestação organizada pela comunidade local em razão dos impactos ambientais gerados pela implantação do parque solar no Rio Gurgueia. Foram feitos registros fotográficos da manifestação e dos impactos causados pelas atividades de implantação do Parque Solar.

O artigo tem o desafio de debater a efetividade da legislação ambiental na perspectiva da participação popular como promotora da cidadania ambiental, tendo como foco os aspectos jurídicolegais, perpassando pela caracterização das questões práticas e dos desafios que necessitam ser superados para um melhor desenvolvimento dessas iniciativas no contexto ambiental nacional. Nessa perspectiva, o conceito de efetividade adotado é o de Chacón (2019).

Com isso, busca-se destacar, entre as legislações apresentadas, os principais aspectos que possibilitam a concretização da cidadania ambiental, prevista como direito fundamental na Constituição Federal (BRASIL, 1988), no aspecto político-legal. Cabe a advertência de que não se pretende exaurir a análise das legislações em todos os seus aspectos, mas somente naquilo que pode ser utilizado como fundamentação para o caso concreto em análise. 
Os três marcos temporais que foram analisados, e observados in loco pelos pesquisadores, com sua respectiva fundamentação legal: (I) Audiência Pública de apresentação do Estudo de Impacto Ambiental e Relatório de Impacto no Meio Ambiente (EIA/RIMA) - 04/09/2018; (II) Impactos ambientais do rompimento das barragens de contenção - 08/02/20; (III) Protesto da comunidade pelos impactos ambientais causados no Rio Gurgueia - 05/03/2020.

A pesquisa procurou trabalhar não a substituição do papel do Estado na gestão dos impactos ambientais gerados pelo empreendimento e sim a perspectiva de que com o engajamento da participação popular pode trazer um ganho de efetividade na legislação ambiental e consequentemente na atuação dos órgãos ambientais concretizando, dessa maneira, os direitos humanos de terceira geração da proteção ambiental (AGRA, 2015).

\section{MEIO AMBIENTE COMO DIREITO FUNDAMENTAL: VERDADE OU UTOPIA?}

Inicialmente, é importante tratar do conceito de "meio ambiente", que foi adotado pelo direito brasileiro e por vários outros países, além de instrumentos internacionais. A expressão "meio ambiente" revela-se redundante, e isso se deve ao fato de que "meio" e "ambiente" são sinônimos, haja vista que ambos significam aquilo que envolve, o entorno onde se vive (MACHADO, 2014).

Antunes (2008, p. 9) explica que "meio ambiente compreende o humano como parte de um conjunto de relações econômicas, sociais e políticas que se constroem a partir da apropriação dos bens naturais que, por serem submetidos à influência humana, transformam-se em recursos essenciais para a vida humana em quaisquer de seus aspectos".

Meio ambiente não se confunde com Ecologia, que segundo Soares (2003, p.2-4) refere-se a "um ramo da biologia no qual os seres vivos são estudados na sua interação recíproca com outros seres vivos e na dependência destes em relação ao mundo inorgânico que os cerca". Explica o autor que por conta da concepção rigorosa de ciência do habitat, a ecologia não tem nenhuma vinculação com a ética e o Direito, pois nesses campos prevalece o comportamento livre do homem, o que é inexistente no mundo da ecologia. Apesar de o conceito de meio ambiente ser menos preciso que ecologia, é ele que alcança a proteção jurídica (SOARES, 2003).

De acordo com Leff (2006, p.38), "o ambiente não é a ecologia, mas a complexidade do mundo". Com esta afirmação, o autor propõe uma reflexão sobre o fenômeno ambiental, deslocandoo das ciências naturais, um lugar tantas vezes reforçado pelas visões biologizantes que preponderam 
neste campo. Em outras palavras, a via hermenêutica por ele escolhida e, consequentemente, a ruptura da dicotomia sujeito-objeto em que essa implica, torna esta reflexão um empreendimento que reposiciona não apenas o ambiente enquanto alteridade, mas, sobretudo o sujeito que o conhece e seu modo de conhecer.

A concepção jurídica de meio ambiente engloba não apenas o conjunto, mas todos os fatores envolvidos. Do mesmo modo, como é um bem de vida, seu conteúdo acaba sendo variável no tempo e no espaço. Hão que ser verificadas as leis e as interações que permitem o equilíbrio entrópico sem o qual não há vida. Trata-se da ideia de macrobem defendida por Leite $(2003$, p. 79$)$ que destaca que "o bem ambiental (macrobem) um bem de interesse público, afeto à coletividade, entretanto a título autônomo e como disciplina autônoma".

Percebe-se, por conseguinte, que o meio ambiente envolve várias dimensões, não apenas o natural. Destaca Silva (2015) que a doutrina clássica aponta três aspectos, quais sejam, natural ou físico, artificial ou construído e cultural. Já o meio ambiente do trabalho, para o mesmo autor, estaria inserido dentro do artificial.

O meio ambiente natural ou físico de acordo com Fiorillo (2008, p. 20): “é constituído pela atmosfera, pelos elementos da biosfera, pelas águas, pelo solo, pelo subsolo, pela fauna e flora. Concentra o fenômeno da homeostase, consistente no equilíbrio dinâmico entre os seres vivos e o meio em que vivem".

As primeiras normas ambientais deram um enfoque utilitarista da natureza, na medida em que era considerada como um bem inesgotável. A Lei 6.938/81, que dispõe sobre a Política Nacional do Meio Ambiente e criou o Sistema Nacional do Meio Ambiente, definia o meio ambiente como "o conjunto de condições, leis, influências e interações de ordem física, química e biológica, que permite, abriga e rege a vida em todas as suas formas". Essa conceituação foi muito inovadora para a sua época, por estender a proteção jurídica a todos os elementos da natureza de uma forma interativa e global.

Somente a partir de 1981, com a promulgação da Lei no 6.938/81, ensaiou-se o primeiro passo em direção a um paradigma jurídico-econômico que holisticamente tratasse e não maltratasse a terra, seus arvoredos e os processos ecológicos essenciais a ela associados. Mas nunca um dia o homem teria imaginado que a água, as plantas, o ar, enfim os bens naturais poderiam tornar-se escassos (SÉGUIN, 2006). Neste sentido que a Lei Fundamental de 1988 atribuiu ao meio ambiente uma configuração jurídica diferenciada, ao classificá-lo como direito de todos e bem de uso comum do povo e essencial à sadia qualidade de vida, atribuindo a esse bem um dimensionamento muito mais significativo. 
O ambiente artificial, consoante Fiorillo $(2008$, p. 21) é compreendido "pelo espaço urbano construído, consistente no conjunto de edificações, e pelos equipamentos públicos". Seu estudo retroage ao início da vida humana e da consequente necessidade de a natureza adequar-se à convivência entre os homens. Na visão de Barros (2008, p. 144), "é aquele estruturado através da cidade e a possibilidade de nela se viver com qualidade de vida, contexto que é disposto através da lei".

Entretanto, o enfoque do direito ao meio ambiente artificial é, realmente, as cidades, que é o espaço onde atualmente habita a maior parte da população brasileira e mundial, cabendo por isso ao poder público promover o acesso ao lazer, à infraestrutura urbana, à moradia, ao saneamento básico, aos serviços públicos e ao transporte. É nesse contexto que a Carta Magna estabelece o direito às cidades sustentáveis, o que deve ser feito por meio de uma política urbana apropriada e participativa, nos moldes do que determinam os artigos 182 e 183, o Estatuto da Cidade (Lei 10.257/01) e Estatuto da Metrópole (Lei 13.089/2015).

A energia elétrica beneficia a sociedade desde a saúde até as linhas de produção, tornando-a indispensável para qualquer sociedade. Inicialmente, o desenvolvimento da energia elétrica no Brasil ocorreu no final do século XIX, a partir da autorização de Dom Pedro II para que os experimentos e aparelhos de Thomas Edison fossem usados no país (ELETROBRAS, 2017). Pouco se tinha dispondo sobre a regulamentação no setor de energia elétrica na Constituição Federal de 1891, que deixava a responsabilidade dos Estados e Municípios para contratos com empresas para provimento desses serviços.

O crescimento urbano e aumento da demanda da população pelos serviços de infraestrutura básica, entre eles o da energia elétrica, provocaram mudanças na matriz energética do Piauí, que antes era dominada praticamente por fonte de energia hidroelétrica, atualmente, possui a energia eólica como principal matriz e grande crescimento da energia solar. O Piauí é hoje o quinto maior produtor de energia elétrica por meio da fonte de energia eólica do Brasil, no mês de Junho/2019 a produção foi de 91,39\% da matriz energética piauiense (ONS, 2019). A energia solar deu um salto em 2018, quando entrou em operação a maior usina solar fotovoltaica da América Latina, situado em território piauiense (AMBIENTE E ENERGIA, 2018)

Apesar de ser considerada uma fonte de energia renovável, a energia solar também causa impactos ao meio ambiente, que podem ser tão danosos, como os das demais matrizes energéticas. Nesse sentido, é válido dizer que a matriz energética brasileira depende dos rumos que o desenvolvimento econômico do país vai seguir. Em todos os casos, o licenciamento ambiental de empreendimentos deve ser obedecido. É possível mitigar muitos dos impactos e, com políticas 
corretas e prévio e transparente estudo de impacto ambiental, proceder a compensações ambientais justas (GOLDENBERG; LUCON, 2007).

O direito ao meio ambiente equilibrado é assegurado pela Constituição como um direito fundamental, que está diretamente relacionado com o direito à vida das presentes e futuras gerações. Entretanto, mesmo o Brasil dispondo de uma vasta legislação ambiental infraconstitucional, isso não tem sido suficiente para a efetiva proteção ao meio ambiente, pois percebe-se um distanciamento entre o que está positivado nas leis e a realidade prática (BEZERRA et al. 2016). As normas jurídicas existem, falta então concretizá-las, mas para tanto, é indispensável a conscientização da sociedade de que a humanidade não é dona da natureza, mas sim, parte dela, aliada à conscientização e sensibilização dos intérpretes legais quando da aplicação da legislação aos casos concretos.

Dentro deste contexto é relevante analisar o significado de direitos fundamentais, segundo Sarlet (2001, p. 75):

\begin{abstract}
A ideia de que os direitos fundamentais integram um sistema no âmbito da Constituição foi objeto de recente referência na doutrina pátria, com base no argumento de que os direitos fundamentais são, em verdade, concretizações do princípio fundamental da dignidade da pessoa humana, consagrado expressamente em nossa Lei Fundamental.
\end{abstract}

Os preceitos inscritos no art. 225 da Carta Política traduzem, na concreção de seu alcance, a consagração constitucional, em nosso sistema de direito positivo, de uma das mais expressivas prerrogativas asseguradas às formações sociais contemporâneas. Essa prerrogativa, que se qualifica por seu caráter de metaindividualidade, consiste no reconhecimento de que todos têm direito ao meio ambiente ecologicamente equilibrado.

Trata-se, consoante o que já proclamou o Supremo Tribunal Federal (RTJ 158/205-206, Rel. Min. CELSO DE MELLO), com apoio em douta lição expendida por Lafer (1995), de um típico direito de terceira geração (ou de novíssima dimensão), que assiste, de modo subjetivamente indeterminado, a todo o gênero humano, circunstância essa que justifica a especial obrigação - que incumbe ao Estado e à própria coletividade (MACHADO, 2014) - de defendê-lo e de preservá-lo em benefício das presentes e futuras gerações, evitando-se, desse modo, que irrompam, no seio da comunhão social, os graves conflitos intergeracionais marcados pelo desrespeito ao dever de solidariedade na proteção da integridade desse bem essencial de uso comum, de todos quantos compõem o grupo social.

Cabe assinalar, que os direitos de terceira geração (ou de novíssima dimensão), que materializam poderes de titularidade coletiva atribuídos, genericamente e de modo difuso, a todos os integrantes dos agrupamentos sociais, consagram o princípio da solidariedade e constituem, por isso 
mesmo, ao lado dos denominados direitos de quarta geração (como o direito ao desenvolvimento e o direito à paz), um momento importante no processo de expansão e reconhecimento dos direitos humanos, qualificados estes, enquanto valores fundamentais indisponíveis, como prerrogativas impregnadas de uma natureza essencialmente inexaurível (LAFER, 1995).

Bonavides (1993, p. 481), confere particular ênfase, dentre os direitos de terceira geração (ou de novíssima dimensão), ao direito a um meio ambiente ecologicamente equilibrado:

Com efeito, um novo pólo jurídico de alforria do homem se acrescenta historicamente aos da liberdade e da igualdade. Dotados de altíssimo teor de humanismo e universalidade, os direitos da terceira geração tendem a cristalizar-se neste fim de século enquanto direitos que não se destinam especificamente à proteção dos interesses de um indivíduo, de um grupo ou de um determinado Estado. Têm primeiro por destinatário o gênero humano mesmo, num momento expressivo de sua afirmação como valor supremo em termos de existencialidade concreta. Os publicistas e juristas já os enumeram com familiaridade, assinalando-lhes o caráter fascinante de coroamento de uma evolução de trezentos anos na esteira da concretização dos direitos fundamentais. Emergiram eles da reflexão sobre tema referentes ao desenvolvimento, à paz, ao meio ambiente, à comunicação e ao patrimônio comum da humanidade.

A preocupação com a preservação do meio ambiente - que hoje transcende o plano das presentes gerações, para também atuar em favor das gerações futuras (MACHADO, 2014) - tem constituído, por isso mesmo, objeto de regulações normativas e de proclamações jurídicas, que, ultrapassando a província meramente doméstica do direito nacional de cada Estado soberano, projetam-se no plano das declarações internacionais, que refletem, em sua expressão concreta, o compromisso das Nações com o indeclinável respeito a esse direito fundamental que assiste a toda a Humanidade.

O direito à integridade do meio ambiente constitui prerrogativa jurídica de titularidade coletiva, refletindo, dentro do processo de afirmação dos direitos humanos, a expressão significativa de um poder deferido, não ao indivíduo identificado em sua singularidade, mas, num sentido verdadeiramente mais abrangente, atribuído à própria coletividade social.

O reconhecimento desse direito de titularidade coletiva, tal como se qualifica o direito ao meio ambiente ecologicamente equilibrado, constitui, portanto, especialmente em sua interconexão com o direito à vida e à saúde, como precedentemente enfatizado, uma realidade a que não mais se mostram alheios ou insensíveis os ordenamentos positivos consagrados pelos sistemas jurídicos nacionais e, também, as formulações normativas proclamadas no plano internacional, como assinalado por autores eminentes (REZEK, 1989). 
A Constituição da República, ao dispor sobre a proteção ao meio ambiente ecologicamente equilibrado, por ela própria reconhecido como "bem de uso comum do povo e essencial à sadia qualidade de vida" (CF, art. 225,"caput"), instituiu, entre nós, verdadeiro "Estado de Direito Ambiental" fundado em bases constitucionais (AMADO, 2011).

Buscando a concretização do direito ao meio ambiente como direito fundamental, é imperiosa a necessidade da efetividade da legislação ambiental. É preciso haver punição sempre que haja o uso irresponsável e inconsequente do desenvolvimento tecnológico que provoque sequelas ao meio ambiente. O Brasil dispõe de grande arsenal de atos normativos que regulamentam a questão ambiental, contudo, há evidentes dificuldades em sua aplicação da maneira, como se apresentam os dispositivos legais.

Sobre o tema, pronunciou-se Prado $(2012$, p.91) da seguinte forma:

As leis ambientais, mormente no Brasil, são em sua maioria, excessivamente prolixas, casuísticas, tecnicamente imperfeitas, quase sempre inspiradas por especialistas do setor afetado, leigos em Direito, ou quando muito de formação jurídica não específica, o que as tornam de difícil aplicação, tortuosas e complexas (...).

Prado (2012) atribui imperfeições as leis ambientais e a dificuldade de aplicação destas ao fato de serem elaboradas por leigos do direito, sendo sobretudo, baseadas em especialistas das áreas afetadas, e que estes fatores podem constituir-se entre as causas para a inefetividade da legislação ambiental brasileira. O estado atual do direito ambiental no Brasil e a nível global, resulta na impossibilidade de se falar em efetividade e muitos menos em sua eficiência, daí a importância de determinar as principais causas e seus efeitos a partir do estudo junto aos operadores do direito, com a finalidade de se conhecer a magnitude do problema e propor possíveis soluções, como foi feito no estudo realizado por Bezerra (2018).

Sustenta-se ainda de acordo com Chacón (2016) que a legislação ambiental tem experimentado um crescimento significativo tanto no direito interno dos Estados quanto no direito internacional através de declarações ou tratados bilaterais, regionais e globais vinculantes. Apesar disso, os problemas ambientais aumentaram em quantidade e severidade, o que mostra que o direito ambiental e a multiplicação de suas normas não conseguiram resolver os problemas ambientais.

Seja por simples desconhecimento dessa legislação pela sociedade, seja pelo descaso dos gestores para com ela, ou seja, pela sua má interpretação e aplicação no caso concreto pelos operadores do direito, o que se verifica na prática, é a completa falta de efetividade de grande parte 
dos normativos legais de proteção ao meio ambiente, causando uma sensação de completo abandono às causas ambientais.

Cafferatta (2007) jurista argentino, destaca que o maior problema do direito ambiental é a falta de efetividade. Sabe-se que existem leis, mas não sabemos como cumprir essas leis. A este respeito Ojeda Mestre (2003), afirma que a legislação ambiental tem sido, especialmente nos países em desenvolvimento, uma lei que sofre raquitismo de eficiência, embora seja evidente que a tensão entre fato e validade não é exclusiva deste ramo do direito.

É importante atentar que existe um permanente estado de tensão entre o imperativo de desenvolvimento nacional (CF, art. 3으, II), de um lado, e a necessidade de preservação da integridade do meio ambiente (CF, art. 225), de outro.

Torna-se essencial reconhecer que a superação desse antagonismo, que opõe valores constitucionais relevantes, dependerá da ponderação concreta, em cada caso ocorrente, dos interesses e direitos postos em situação de conflito, em ordem a harmonizá-los e a impedir que se aniquilem reciprocamente, tendo-se como vetor interpretativo, para efeito da obtenção de um mais justo e perfeito equilíbrio entre as exigências da economia e as da ecologia, o princípio do desenvolvimento sustentável, tal como formulado em conferências internacionais (a "Declaração do Rio de Janeiro sobre o Meio Ambiente e Desenvolvimento de 1992", "p. ex.") e reconhecido em valiosos estudos doutrinários que Ihe destacam o caráter eminentemente constitucional (FIORILLO, 2008).

\section{O EXERCÍCIO DA CIDADANIA AMBIENTAL EM UMA EXPERIÊNCIA}

A sociedade exerce um papel fundamental na proteção ambiental e essa participação popular vem ganhando cada vez mais importância ao longo dos anos, principalmente em regiões distantes dos grandes centros políticos. Impulsionados pelo aumento da degradação ambiental bem como pela a ausência (e/ou conivência) do Poder Público, a população vem tentando concretizar esse entendimento que Gadotti (2008) denomina de "o cuidar de toda a comunidade" para com a natureza (GADOTTI, 2008, p. 12).

Um suspiro dessa nova racionalidade por parte da população afetada pelos impactos socioambientais de grandes obras pode ser contextualizada no caso na instalação do Parque Solar em São Gonçalo do Gurgueia, no estado do Piauí (Nordeste do Brasil). O empreendimento foi anunciado 
(10 semestre de 2017) como a "grande salvação" para parte do extremo sul piauiense, especificamente para o pequeno município no sul do estado, trazendo inúmeros ganhos principalmente na esfera socioeconômica como geração de emprego/renda para a localidade. Esse argumento é comumente utilizado não só nesse empreendimento em específico, mas em diversos obras que possuem como característica principal os grandes impactos ambientais (PALHETA; NASCIMENTO; SILVA, 2017; ACSELRAD, 2010).

Seguindo o processo estabelecido pelas Resoluções CONAMA 01/1986, 09/1987 e 237/1997, ocorreu uma audiência pública no dia 04/09/2018 como forma de discussão dos resultados encontrados no Estudo de Impacto Ambiental (EIA) e respectivo Relatório de Impacto no Meio Ambiente (RIMA). Cabe destacar alguns pontos observados na audiência que, de alguma maneira, dificultam a participação popular nas discussões.

Na Resolução CONAMA 09/87 dispõe que o local da audiência deverá ocorrer em ambiente acessível aos interessados (Art. 2, §4으) bem como, caso exista a necessidade, em função da localização geográfica dos solicitantes, e da complexidade do tema, poderá haver mais de uma audiência pública sobre o mesmo projeto (Art. 2ㅇ, §5ㅇ) (BRASIL, 1987). Nesse sentido, cabe salientar que o local escolhido para a audiência não comportava todas os interessados em razão da grande área de influência indireta do projeto que engloba mais de três municípios da região (Corrente -26.709 hab.; Gibués - 10.694 hab.; São Gonçalo do Gurgueia - 3.057 hab.) (IBGE, 2019) e respectivo número de interessados

Na audiência, que ocorreu no Centro de Referência de Assistência Social (CRAS), diversas pessoas não foram acomodadas devidamente para acompanhar as discussões que ocorreram por mais de quatro (4) horas. Parte dos interessados não conseguiram entrar no ambiente tanto em razão da lotação quanto do desconforto térmico. Ademais, o dia da audiência (quarta-feira), assim como a hora (17:00-21:00), impossibilitou que pessoas de outras regiões e da zona rural comparecessem. Todos esses aspectos, de alguma maneira, restringem a participação popular. Pensando nestas situações foi que a Resolução CONAMA 09/87 abriu a possibilidade de realizar diversas audiências em locais distintos justamente para difundir e propiciar as discussões para todos os interessados. Esse entendimento pode ser interpretado desde Brasil (1987) até Chacón (2019) baseando-se nos princípios da informação e da participação popular.

Nesse sentido não cabe apenas fomentar uma participação formal da população. É necessário dispor dos meios para que isso ocorra de maneira concreta. Portanto, parece pertinente falar de ressignificação da cidadania, que exprime de forma emblemática os desafios do presente: de um lado, seu alargamento conceitual aponta para a necessidade de redefinir os termos da convivência 
nas sociedades democráticas; do outro, sua inflação normativa, evidencia a ausência de respostas e de alternativas de encaminhamento material (LAVALLE, 2003).

No processo da audiência, que era presidida pelo órgão ambiental responsável (Secretaria de Meio Ambiente do Estado do Piauí-SEMAR/PI) conforme Resolução CONAMA 09/87 e Lei Complementar Federal 140/11, ficava evidente que as questões ambientais foram deixadas de lado em virtude do argumento emprego/renda. Esse fator era a todo momento destacado pelos responsáveis do empreendimento. Salvo raras exceções presentes no debate (instituição de ensino, associação de moradores e alguns políticos locais), grande parte dos presentes não fez questionamentos sobre os possíveis impactos ambientais gerados na fase de implantação e operação do projeto.

Essa conjuntura pode ser analisada por duas vertentes. A primeira diz respeito à forma de apresentação dos resultados para a comunidade. Diversos dados excessivamente técnicos foram apresentadas em uma linguagem que não facilitava a compreensão por parte da população. Essa forma de exposição de grandes empreendimentos ocorre com frequência e é amplamente questionada (PALHETA; NASCIMENTO; SILVA, 2017).

A segunda hipótese reside na oportunidade trazida pela empresa para aquela localidade, fazendo com que qualquer questionamento mais crítico pudesse "afastar" aquele projeto da cidade. Essa ótica pode ser apontada em razão dos dados econômicos do município: 56,3\% da população economicamente ativa recebe até $1 / 2$ salário mínimo (IBGE, 2019). O empreendimento era a chance de modificar essa realidade. No discurso de abertura da audiência o Prefeito da cidade afirmou: “(...) Nossa cidade tem uma grande parcela da população abaixo da linha da pobreza e a vinda do Parque Solar será decisiva para a mudança da nossa realidade, o que nos deixa muito feliz e com grande expectativa!" (SÃO GONÇALO DO GURGUEIA, 2018).

A expectativa gerada foi confirmada. Com a obtenção da Licença Prévia (LP) e consequente Licença de Instalação (LI) (BRASIL, 1986), a construção do Parque Solar iniciou em 22/10/2018 em diversas etapas e com a contratação de aproximadamente 1.500 trabalhadores de diversas regiões do Piauí (assim como do município), do Brasil e da Itália (sede da responsável pelo empreendimento) (RIBEIRO, 2019). Para uma pequena cidade no interior do Piauí que possui cerca de 3.000 habitantes, e $60 \%$ da população localizada abaixo da linha da pobreza (IBGE, 2019), as modificações foram profundas.

Queiroz e Veiga (2012) afirmam que impactos sociais e à saúde das populações de pequenas localidades longe dos grandes centros urbanos com a chegada de empreendimentos energéticos de 
grande porte são inúmeros. Aumento dos índices de doenças sexualmente transmissíveis (DSTs), alcoolismo, depressão, prostituição, uso de entorpecentes são alguns exemplos que podem ser trazidos à baila (QUEIROZ; VEIGA, 2012; UTSUNOMIYA, 2014). Além desses, a intensa movimentação de pessoas e demanda crescente por serviços como hospedagem, saúde, lazer e alimentação induziram uma verdadeira alteração na dinâmica social no município de São Gonçalo e cidades vizinhas.

Apesar desses fatores, a sociedade até então não tinha se organizado para questionar os impactos socioambientais gerados pela implantação do Parque Solar. Dentre as alterações realizadas merece destaque a construção de estruturas para o barramento das águas das chuvas (barragens de contenção) e consequente redução do escoamento superficial nas áreas do Parque. Com o alto índice pluviométrico ocorrido no final de 2019, as bacias construídas no entorno do parque ficaram totalmente cheias e se romperam. As enxurradas desceram da Serra de Santa Marta, onde fica o Parque, para as áreas mais baixas, levando muito entulho, areia e lama, provocando em fevereiro de 2020, o rompimento de barragens do complexo que causou destruição de fazendas/propriedades (Figura 3A), morte de animais e aterramento de trecho do Rio Gurgueia (Figura 3C), além de nascentes na região (Figura 3B).

De acordo com a regulamentação prevista na Constituição Federal de 1988 (Art. 225, IV), na Resolução CONAMA 01/86 (Art. 5ㅇ, II) e na PNMA (Art. 9ㅇ, III) todos os potenciais impactos ambientais devem ser identificados e classificados, devendo, além dessa classificação, propor medidas mitigadoras para os impactos negativas a fim de minimizar os prováveis danos ambientais (SANCHEZ, 2006). A intenção da legislação ambiental é justamente minimizar os riscos e ter, de antemão, um planejamento estabelecido para eventuais sinistros que possam ocorrer. No EIA/RIMA elaborado para obra não existe nenhuma menção sobre a construção das barragens de contenção (ALBA ENERGIA, 2017). A SEMAR/PI também afirmou que não tinha conhecimento dessas estruturas (CALIXTO, 2020a).

A omissão dessa informação no EIA/RIMA por si só constitui uma infração administrativa e um crime ambiental. Essa interpretação pode ser levantada com base no art. 69-A da Lei Federal no 9.605/98, com pena cominada de reclusão, de 3 (três) a 6 (seis) anos, e multa em caso de comprovação do dolo e de detenção, de 1 (um) a 3 (três) anos na modalidade culposa. Ademais, com base no § 2은 do mesmo artigo, a pena é aumentada de $1 / 3$ (um terço) a 2/3 (dois terços) se há dano significativo ao meio ambiente em decorrência do uso da informação falsa, incompleta ou enganosa (BRASIL, 1997).

De acordo com Brasil (1997), o objetivo do licenciamento ambiental é obter, junto ao empreendedor, os dados adequados para avaliar a viabilidade ambiental do empreendimento, levando em consideração as ações efetivas ou potencialmente poluidoras ou daquelas que, sob 
qualquer forma, possam causar degradação ambiental, considerando as disposições legais. O poder de polícia ambiental, efetuado tanto de maneira preventiva (licenciamento) quanto repressiva (fiscalização), deve ser exercido de maneira ampla. Nesse sentido, a cooperação entre empreendedor e órgãos ambientais é um dos pilares do sistema ambiental brasileiro.

Figura 1 - Impactos do rompimento: (A) Destruição de propriedades; (B) Assoreamento de nascente; (C) Assoreamento de trecho do Rio Gurgueia; (D) Voçoroca gerada em terreno.
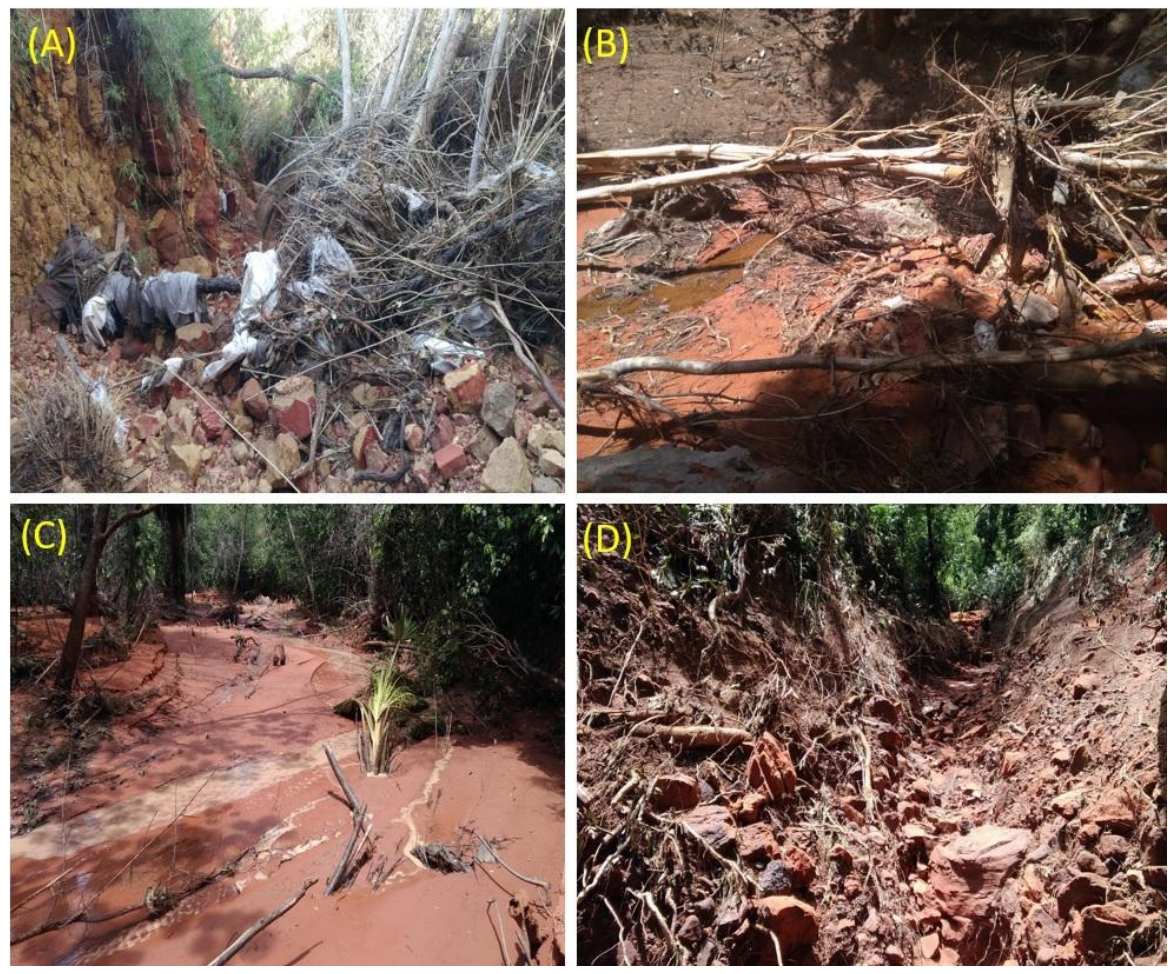

Fonte: Elaborada pelos autores e com base em Calixto (2020a).

O rompimento aconteceu no dia 05/02/2020 e a Secretaria de Meio Ambiente do Estado do Piauí (SEMAR/PI) apenas soube de maneira oficial no dia 12/02/2020, informando que não sabiam da construção daqueles reservatórios no empreendimento (CALIXTO, 2020a). O prefeito de São Gonçalo, que outrora comemorava o lançamento do empreendimento, foi pessoalmente à SEMAR, em Teresina, protocolar um ofício solicitando ajuda e informando que:

A prefeitura não tem muito que fazer diante dessa situação, somos uma cidade pequena, com apenas 24 anos de emancipação, 3.400 habitantes, não temos aparato técnico. Só temos o secretário municipal de Meio Ambiente correndo do jeito que dá e que não tem qualificação nenhuma na área. Então viemos protocolar um ofício na SEMAR, que foi quem concedeu a licença ambiental para 
o parque solar. A única coisa que a gente pode fazer é expedir ofício pro Governo (CALIXTO, 2020b).

De acordo com a fiscalização executada pela SEMAR, e também por visita in loco dos autores, 30 famílias foram atingidas (CARVALHO, 2020a). A água e lama invadiram as terras de agricultores dos povoados de Grotão da Lapa, Buritizinho e Lapa (Figura 3A). Com a destruição das plantações de milho e melancia, que são os principais produtos da região, a renda prevista para a Semana Santa, no mês de abril, foi perdida. A pequena criação de gado, atividade também realizada na região, também foi inviabilizada. Toda criação foi deslocada para outras áreas pois quando os animais iam beber água no rio morriam atolados na lama. $O$ processo erosivo soterrou os brejos e nascentes que existiam nas propriedades.

Afora as omissões presentes no próprio licenciamento ambiental que configuram crime e infração administrativa ambiental, os danos ambientais causados pelo rompimento das barragens se enquadram em outros tipos penais. Segundo Brasil (1997), causar poluição de qualquer natureza em níveis que resultem ou possam resultar em danos à saúde humana, ou que provoquem a mortandade da biodiversidade é passível a pena - reclusão, de um a quatro anos, e multa (Art. 54, caput). Essa pena pode ser aumentada (de uma a cinco anos) caso a poluição ocasionar poluição hídrica que torne necessária a interrupção do abastecimento público de água de uma comunidade (Art. 54, III) (BRASIL, 1997).

A omissão por parte do empreendedor em não notificar oficialmente o dano ambiental também gera responsabilidades administrativa e penal. $O$ empreendedor dificultou a ação fiscalizadora do Poder Público no que cabe a apuração dos danos ambientais causados no momento em que esse não foi de imediato informado. Nesse sentido, a Lei Federal no 9.605/97 prevê a detenção, de um a três anos, e multa.

Pela fundamentação legal apresentada, no que cabe à Lei de crimes ambientais, o empreendedor se enquadra em pelo menos três tipos penais distintos (Arts. 54, 69, 69-A) (BRASIL, 1997). Apesar de configurarem bons instrumentos de comando/controle, as multas/penalidades não conseguem trazer o ambiente ao status de antes do impacto ambiental (SÁNCHEZ, 2006). Nessa ótica, os principais afetados, que são as comunidades da região, continuam sem poder exercer suas atividades que são intimamente ligadas ao ambiente em que vivem.

De acordo com Palheta, Nascimento e Silva (2017), os impactos ambientais são potencializados quando atingem populações rurais que vivem diretamente do uso da natureza. Isso se deve pela sua relação direta com o manejo solo e da água bem como sua dependência das sazonalidades do meio 
ambiente. A enxurrada também atingiu as nascentes dos riachos (Boqueirão dos Macacos, Buritizinho e Buriti do Meio) da localidade, além da borda da serra em que ocorreu todo o processo de carreamento. De acordo com relatos dos moradores existem áreas com quase dez metros de altura só de areia e entulhos.

Em virtude desses impactos ambientais amplamente divulgados tanto pelos portais de mídias locais (CARVALHO, 2020a; CALIXTO, 2020a; CALIXTO, 2020b) quanto pelas redes sociais, a população resolveu tentar se articular organizando um protesto solicitando que providencias fossem tomadas pelo Poder Público e pela empresa, principalmente em relação ao assoreamento dos trechos do Rio Gurgueia.

A organização do movimento foi feito por meio das redes sociais (Whatsapp - Grupo "Manifestação Rio Gurgueia", Facebook) através do compartilhamento de notícias/fotos dos impactos causados no Rio e não teve uma única liderança/idealizador. A conexão entre os integrantes residia apenas no sentimento de insatisfação causada pela atuação da empresa. A ideia do protesto foi cogitada por diversos participantes que estavam inseridos nas redes e cada um contribuiu nas suas possibilidades de maneira voluntária. Cada participante ofereceu uma ação/estratégia/atividade que possuía alguma familiaridade. Por exemplo, quem trabalhava com locação de vans disponibilizou veículos para levar os manifestantes; os cartazes foram elaboradas por docentes das escolas municipais; o material de confecção dos cartazes/faixa foi doado por uma papelaria local; o lanche foi organizado por pessoas que trabalham na atividade de alimentação.

Leite e Ayala (2004) argumentam que a democracia ambiental deve permitir que os interesses e direitos das futuras gerações não sejam lesados, não apenas por meio da fiscalização da idoneidade da representação de seus interesses, mas, sobretudo, mediante a reserva da decisão à participação de seus legítimos interessados assim como pelo direito à resistência frente aos danos ambientais.

No Brasil, essa reserva de decisão mostra-se possível graças à proteção de condições e garantias de que, sempre que se identifique potencial referência a seus interesses, o processo democrático atual deve limitar sua atuação, reservando tais problemas pontuais para a apreciação futura e pertinente de seus interessados, protegendo em um novo sentido republicano a participação de titulares não atuais, e sobretudo a autonomia política desses titulares, atributos que lhes são conferidos juridicamente (participação e autonomia política), mediante a solução dogmática que opta pela instituição de cláusulas constitucionais de bloqueio.

Acselrad (2010) destaca que as mobilizações socioambientais possuem um poder transformador da realidade sobretudo quando são ouvidos pelos órgãos governamentais 
competentes. Essa reflexão feita pelo autor ganha uma aplicação prática no caso de São Gonçalo do Gurgueia. Após a pressão exercida pela mobilização social, e em razão da sua atividade fim, a SEMAR/PI determinou que a empresa seria responsável por realizar a perfuração de três poços artesianos nas localidades Boqueirão dos Macacos, Buritizinho e Buriti do Meio (CARVALHO, 2020a). A potencial construção de mais poços, caso houvesse a necessidade, seria avaliada junto à comunidade, destacando a importância do abastecimento de água diretamente no local, sem necessidade de entrega de água mineral e potáveis. Para mais, foi determinada a construção de estruturas para contenção de sedimentos nos riachos impactados e implantadas barreiras drenantes na região do parque solar, impedindo o carreamento de mais sedimentos (CARVALHO, 2020b). Até o presente momento não houve nenhuma providência tomada para o ressarcimento dos danos causados, para além da construção de poços, na comunidade.

Contudo, é importante destacar que em contato com a Promotoria de Justiça do município de Gilbués-PI, obteve-se a informação de que, após o recebimento de denúncias da população afetada pelo empreendimento, foi instaurado o Inquérito Civil no 02/2020 - 000517-208/2019 em 10 de março de 2020, com o objetivo de investigar a existência de dano ambiental em decorrência da operação de Parque Solar da empresa ENEL GREEN POWER 22 S/A no município de São Gonçalo do Gurguéia-PI. Essa investigação ministerial ainda se encontra em uma fase instrutória, estando prevista a realização de uma vistoria ambiental pela Coordenadoria de Pericias do Ministério Público do Estado do Piauí. Após receber o laudo relativo a essa vistoria, e caso constatado o dano, a Promotoria buscará a via extrajudicial ou judicial para a respectiva recomposição.

Ao se socorrer do Ministério Público a população de São Gonçalo e das outras áreas atingidas pelo parque solar, demonstra que é conhecedora dos seus direitos, mas além disso, demonstra a apropriação da população do sentimento de proteção ao meio ambiente. Esse desejo de agir para impedir que danos aconteçam aos recursos naturais da região, expressa o espírito da cidadania que é defendido no presente estudo, e que vai exigir da atividade jurisdicional do Estado, o mesmo zelo na aplicação da legislação ambiental, visando sua efetividade.

Neste sentido, pode-se afirmar que ao dar efetividade a legislação ambiental pertinente ao caso concreto, o Estado estará concretizando a cidadania ambiental exercida pela população e garantindo a proteção do meio ambiente nos termos defendidos pela Constituição Federal.

Não se pode deixar de observar que o caput do art. 225 da Carta Magna brasileira, constitui no texto político fundamental brasileiro o punctum de referência imediata do reconhecimento da abertura dogmática amiga ao reconhecimento da cidadania ambiental brasileira. Nos precisos termos em que se afirma o caráter difuso do bem ambiental (BRASIL, 1988) e a estrutura de um sistema de 
responsabilidades compartilhadas entre todos, com uma orientação inclusiva, que inclui não só aqueles que não podem exercer regularmente os direitos políticos, mas também as futuras gerações.

A referência constitucional à cidadania ambiental permite o reconhecimento dogmático da juridicidade de um direito que é ao mesmo tempo definido pela participação direta e integral nos processos de decisão, pela inclusividade subjetiva e pela intergeracionalidade. A construção de uma cidadania ambiental no Brasil, sofre da mesma carência que todas as outras questões de caráter coletivo, e que envolvam direitos de todos indistintamente.

Esse exemplo de São Gonçalo é uma exceção do que outrora já foi regra. O Brasil é o país que conta com o mais diversificado histórico de movimentos sociais da América Latina, destacando-se a década de 70, e a Constituição de 1988. Os conselhos gestores de políticas públicas, com destaque para o orçamento participativo, contribuíram para a implantação do projeto participativo como princípio da sociedade brasileira bem como diversas formas de participação popular garantidos pelo texto constitucional (DAGNINO; TATAGIBA, 2010).

As questões ambientais são visíveis e compreensíveis a uma parcela da população, que simplesmente as ignoram, ou por conveniência, ou por conivência. Um paradoxo complicado de ser resolvido, uma vez que se reconhece a importância do meio ambiente para a continuidade da vida humana. Contudo, sensibilizar as pessoas para construção de uma cidadania ambiental, que não tem sanadas necessidades fisiológicas básicas, e com isso não podem pensar no futuro, mas apenas no presente, é um trabalho árduo e que carece de projetos e ações de maior alcance e relevância do que as que vem sendo praticadas.

A bandeira que se levanta é do crescimento econômico, progresso, redução das desigualdades sociais, mais o que de fato se apresenta, é a ampliação da destruição ambiental, e a ampliação do abismo econômico entre as classes. Não há ainda no país uma consciência ou nas palavras de Souza (2003), uma "responsabilidade coletiva", que possibilite a posição de destaque que as questões ambientais merecem. A questão ambiental levantada no cartaz "S.O.S Gurgueia” consegue trazer para o plano concreto as dimensões ambientais levantadas por Rodrigues e Derani (2013). Não é possível realizar uma total separação entre as questões ambientais e sociais. Didaticamente aparecem separadas, contudo, na realidade, são indissociáveis (MARTíNEZ ALIER, 2007). 


\section{CONSIDERAÇÕES FINAIS}

A dogmática jurídica assim considerada, alerta que o compromisso de lealdade ecológica remete à consideração de que a cidadania ambiental não só recupera a participação daqueles que eventualmente não estejam ou nunca puderam estar representados nos moldes das democracias representativas liberais, mas também inclui aqueles que nunca poderão ser representados.

A pesquisa evidenciou que a participação da população alertando às autoridades sobre os impactos soicoambientais negativos gerados pela implantação do Parque de Energia Solar em São Gonçalo do Gurguéia-Piauí, caracterizou-se como uma forma de exercício da cidadania ambiental e com isso foi possível atingir a efetividade da legislação ambiental vindicada por àquela população.

O risco, compreendido como maneira de estabelecimento de vínculos com o futuro, revela custos que podem ou não querer ser suportados pela sociedade, que, em uma postura de participação, precisa instituir necessariamente mecanismos de decisão para a avaliação da conveniência ou não de suportá-los, nos quais os dados do futuro também precisam ser levados em consideração, notadamente os interesses/direitos das futuras gerações

No caso de São Gonçalo ficou nítido os hiatos e dificuldades presentes na efetividade da legislação ambiental. Apesar de bem regulamentada pelas leis, instrumentos como a audiência pública, o estudo de impacto ambiental e a fiscalização das ações que podem causar danos ambientais ainda são insuficientes para garantir um meio ambiente ecologicamente equilibrado. A atuação da mobilização social, por meio da cidadania ambiental, afirmando seu direito subjetivo foi importante para alertar o Poder Público frente aos impactos socioambientais causados pelas obras do Parque Solar.

A cidadania ambiental aparece com uma alternativa promissora, mas ainda tímida na sociedade atual, para proteção dos bens difusos. A construção desse paradigma é uma realidade distante, em face da situação de crise em que se vive a sociedade, marcada pelas desigualdades sociais, pelo empobrecimento da maioria da população, degradação ambiental, em escala global, entre tantos outros problemas. Exige essa "nova cidadania" a transformação para um novo paradigma de Estado, que pressupõe a repolitização da realidade e da própria cidadania, bem como uma carta de respeito de direitos ao ambiente sadio

Essa correta compreensão dos limites, especificidades e conteúdo das relações estabelecidas entre direito e ambiente perante os riscos demonstra o necessário desenvolvimento de uma dimensão transdisciplinar que permita a integração completa de todos os domínios funcionais à organização da 
compreensão autenticamente ecossistêmica dos problemas ambientais, pois somente dessa maneira a decisão poderá ser corretamente ordenada.

Exige-se uma perspectiva inclusiva, que permita a participação pluralística de atores, dados e valores multirreferenciais, em uma postura de recuperação ativa do sentido republicano da cidadania. E, para isso, o modelo normativo não basta; o modelo normativo de cidadania é insuficiente, porque não lida de forma satisfatória nem com as futuras gerações, nem com os problemas da participação e do acesso aos espaços de decisão, todos necessários ao desenvolvimento de sua dimensão ambiental.

Para permitir que seja possível o desenvolvimento de um autêntico modelo de cidadania ambiental, deve-se sempre levar a sério os seus princípios e, fundamentalmente, a Constituição, em seu efeito catequizador. Se apenas isto for feito, uma grande e complexa mudança já se terá operado no domínio da efetividade do direito do ambiente e na construção de uma identidade ambiental brasileira.

\section{REFERÊNCIAS}

ACKERMAN, Bruce Rosenkrantz. "Tres concepciones de la democracia constitucional", in ACKERMAN, Bruce et al. Fundamentos y alcance del control judicial de constitucionalidad. Madri: Centro de Estudios Constitucionales, 1991.

ACSELRAD, H. Ambientalização das lutas sociais - o caso do movimento por justiça ambiental. In: Estudos avançados 24 (68), p.103-119, 2010.

AGRA, W. M. Magna Carta: um pacto feudal que foi densificado como uma carta de direitos. In: Revista Brasileira de Estudos Constitucionais, Belo Horizonte, v. 33, p. 595-618, 2015.

ALBA ENERGIA. Parque Solar São Gonçalo: estudo de impacto ambiental -EIA. Salvador: Ambcon, 2017.

ALVES, S.G.; REIS NETO, A.F.; BARROS JUNIOR, A.P. Parques eólicos: a "sujidade" da energia limpa em Acaraú e Canoa Quebrada - CE. In: Revista Eletrônica do Prodema, v. 13, n. 2, p.72-87, 2019.

AMADO, Frederico Augusto Di Trintade. Direito Ambiental Esquematizado. 2. ed. São Paulo: Método, 2011.

AMBIENTE E ENERGIA. Empresários do Paraná apostam no mercado de energia solar. 2019. Disponível em: $<$ https://www.ambienteenergia.com.br/index.php/2019/01/empresarios-paranaapostam-mercado-de-energia-solar/35582\#.XEp1ilxKjIV>. Acesso 15 nov. 2020. 
BAHIA, C.M.; MELO, M.E. O estado de direito ecológico como instrumento de concretização de justiça ambiental. Revista de Direito Ambiental e Socioambientalismo, v. 4, n. 2, p. 38-59, 2018.

BALLAR, Rafael González. Verdades incómodas sobre La gobernabilidad ambiental en Costa Rica. San José: Editorial Jurídica Continental, 2007.

BEZERRA, Ana Keuly Luz. Práticas de Justiça: A atuação dos operadores do direito no enfrentamento das questões ambientais. Tese (Doutorado em Desenvolvimento e Meio Ambiente) - Programa de Pós-Graduação em Desenvolvimento e Meio Ambiente da Universidade Federal do Piauí. Teresina, p. 161. 2018.

BRASIL. Constituição Federal de 1988. Disponível em:

http://www.planalto.gov.br/ccivil_03/leis/I9605.htm. Acesso em: 15 nov. 2020.

BRASIL. Resolução CONAMA 01/86. Os critérios básicos e as diretrizes gerais para uso e implementação da Avaliação de Impacto Ambiental como um dos instrumentos da Política Nacional do Meio Ambiente. Disponível em: http:

http://www2.mma.gov.br/port/conama/res/res86/res0186.html. Acesso em: 15 nov. 2020.

BRASIL. Resolução CONAMA 09/87. Dispõe sobre a realização de Audiências Públicas no processo de licenciamento ambiental. Disponível em:

http://www2.mma.gov.br/port/conama/legiabre.cfm?codlegi=60. Acesso em: 15 nov. 2020.

BRASIL. Resolução CONAMA 237/97. Dispõe sobre licenciamento ambiental; competência da União, Estados e Municípios; listagem de atividades sujeitas ao licenciamento; Estudos Ambientais, Estudo de Impacto Ambiental e Relatório de Impacto Ambiental. Disponível em:

httphttp://www2.mma.gov.br/port/conama/res/res97/res23797.html. Acesso em: 15 nov. 2020.

BRASIL. Lei 6.938/81. Dispõe sobre a Política Nacional do Meio Ambiente, seus fins e mecanismos de formulação e aplicação, e dá outras providências. Disponível em: http http://www.planalto.gov.br/ccivil_03/LEIS/L6938.htm. Acesso em: 15 nov. 2020.

BRASIL. Lei 9.605/97. Dispõe sobre as sanções penais e administrativas derivadas de condutas e atividades lesivas ao meio ambiente, e dá outras providências. Disponível em:

http://www.planalto.gov.br/ccivil_03/leis/19605.htm. Acesso em: 15 nov. 2020.

CAFFERATTA, Nestor. De la efectividad del derecho ambiental. La Ley. 02 oct./2007.

CALIXTO, V. SEMAR não sabia da construção das bacias que romperam em parque solar no Sul do Piauí. In: Portal de notícias Piauí Hoje. 2020a. Disponível em:

$<$ https://piauihoje.com/noticias/municipios/empresa-omitiu-rompimento-de-bacias-em-parquesolar-as-autoridades-do-estado-343326.html>. Acesso em: 15 nov. de 2020

CALIXTO, V. Prefeito pede socorro após rompimento em parque solar em São Gonçalo Gurguéia. In: Portal de notícias Piauí Hoje. 2020b. Disponível em:

https://piauihoje.com/noticias/municipios/prefeito-pede-socorro-ao-governo-do-estado-aposrompimento-em-bacias-de-parque-solar-343386.html. Acesso em: 15 nov. de 2020

CARVALHO, José Murilo de. Cidadania no Brasil: o longo caminho. 11.ed. Rio de Janeiro. Civilização Brasileira, 2008. 
CARVALHO, M. Após vistoria, Semar publica medidas a serem tomadas em São Gonçalo do Gurguéia. In: Portal Oficial do Governo do Estado do Piauí. 2020a. Disponível em:

$<$ https://www.pi.gov.br/noticias/apos-vistoria-semar-publica-medidas-a-serem-tomadas-em-saogoncalo-do-gurgueia/>. Acesso em: 15 nov. de 2020.

CARVALHO, M. Secretária de Meio Ambiente visita área de extravasamento de água em São Gonçalo do Gurguéia. In: Portal Oficial do Governo do Estado do Piauí. 2020b. Disponível em: < https://www.pi.gov.br/noticias/sadia-castro-visita-area-de-extravasamento-de-agua-em-saogoncalo-do-gurgueia/>. Acesso em: 15 nov. de 2020

CHACÓN, Mario Peña. El camino hacia la efectividad del derecho ambiental. Revista de Direito Ambiental. v. 83/2016, p.39-56, jul-set/2016.

CHACON, M. P. O caminho para a efetividade do direito ambiental. In: Sequência, n.83, p.87-95, 2019.

DAGNINO, Evelina; TATAGIBA, Luciana. Movimentos sociais e participação institucional: repertórios de ação coletiva e dinâmicas culturais na difícil construção da democracia brasileira. Revue Internationale de Politique Comparée 17(2)-Número especial sobre Répertoires d'action collective em Amérique Latine, [s.d.]. 2010. Disponível em http://www.nepac.ifch.unicamp.br/pt$\mathrm{br} / \mathrm{pa} /$ mouvements-sociaux-et-participation institutionnelle-r\%C3\%A9pertoires-d\%E2\%80\%99actioncollective-et. Acesso em: 30 out. 2020.

FIORILLO, Celso Antonio Pacheco. Curso de direito ambiental brasileiro. 9.ed. São Paulo: Saraiva, 2008.

GADOTTI, Moacir. Educar para a sustentabilidade: uma contribuição à década da educação para o desenvolvimento sustentável. São Paulo: Editora e Livraria Instituto Paulo Freire, 2008.

GOLDEMBERG, José; LUCON, Oswaldo. Energia e meio ambiente no Brasil. Estudos avançados, São Paulo, v. 21, n. 59, p. 7-20, Apr. 2007. Disponível em:

$<$ http://www.scielo.br/scielo.php?script=sci_arttext\&pid=S0103-

40142007000100003\&Ing=en\&nrm=iso>. Acesso em 15 nov. 2020. https://doi.org/10.1590/S0103$\underline{40142007000100003 .}$.

INSTITUTO BRASILEIRO DE GEOGRAFIA E ESTATÍSTICAS (IBGE). IBGE Cidades, 2019. Disponível em: https://cidades.ibge.gov.br/brasil/pi/sao-goncalo-do-gurgueia/panorama. Acesso em: 15 nov. de 2020

LAVALLE, A. G. Cidadania, igualdade e diferença. Lua nova, São Paulo: CEDEC, n. 59, 2003, p. 75-94.

LEITE, José Rubens Morato; AYALA, Patryck de Araújo. Direito ambiental na sociedade de risco. 2.ed. Rio de Janeiro: Forense, 2004.

MACHADO, Paulo Affonso Leme. Direito Ambiental Brasileiro.22.ed. São Paulo: Malheiros, 2014

MARTÍNEZ ALIER, J. O ecologismo dos pobres: conflitos ambientais e linguagens de valoração. São Paulo: Contexto, 2007.

MESTRE, Ramón Ojeda. La cien caras del derecho ambiental. Medio Ambiente \& Derecho. Revista Electrónica de Derecho Ambiental. n.9. Universidad de Sevilla, 2003. 
MIGUEL, L. F. Teoria democrática atual: esboço e mapeamento. BIB, São Paulo: ANPOCS, n.59, 2005, p. 5-42.

NAVARRO, Gabriela Braga. Hermenêutica filosófica e direito ambiental: concretizando a justicia ambiental. São Paulo, 2015.

ONS. Boletim Mensal de Geração por Estado: Junho de 2019. Disponível em: $<$ http://www.ons.org.br/paginas/resultados-da-operacao/boletins-da-operacao $>$. Acesso em $30 \mathrm{de}$ out. 2020.

PALHETA, J. M.; NASCIMENTO, F. R.; SILVA, C. N (Org.). Grandes empreendimentos e impactos territoriais no Brasil. Belém: GAPTA/UFPA, 2017.

PRADO, Luiz Regis. Direito Penal do Ambiente. 3. ed. São Paulo: RT, 2012.

QUEIROZ, A. R. S.; VEIGA, M. M. Análise dos impactos sociais e à saúde de grandes empreendimentos hidrelétricos: lições para uma gestão energética sustentável. Revista Ciência \& Saúde coletiva, Rio de Janeiro, v. 17, n. 6, 2012.

RIBEIRO, I. Maior parque solar da América Latina está sendo instalado em São Gonçalo do Gurgueia. In: Portal de Notícias Piauí 180 graus. 2019. Disponível em: <https://180graus.com/piaui-180/maiorparque-solar-da-america-latina-esta-sendo-instalado-em-sao-goncalo-do-gurgueia>. Acesso em: 15 nov. de 2020.

REZEK, José Francisco. Direito Internacional Público. São Paulo: Saraiva, 1989.

RODRIGUES, Horácio Wanderlei; DERANI, Cristiane. Educação ambiental: o direito, caminho para a consciência ambiental. In: CAÚLA, Bleine Queiroz et al. Diálogo ambiental, constitucional e internacional. Fortaleza: Premius,2013.

SÁNCHEZ, L. E. Avaliação de Impacto Ambiental: conceitos e métodos. São Paulo: Oficina de. Textos, 2006.

SÃO GONÇALO DO GURGUEIA. Com grande participação popular, audiência pública para instalação da Usina Solar é realizada em São Gonçalo do Gurgueia. In: Portal Oficial da Prefeitura de São Gonçalo do Gurguéia. 2018. Disponível em:

<http://saogoncalodogurgueia.pi.gov.br/site/noticias/74>. Acesso em: 15 nov. de 2020

SOUZA, Jessé. A construção social da subcidadania: para uma sociologia política da modernidade periférica. Belo Horizonte: UFMG, Rio de Janeiro: IUPERJ, 2003.

UTSUNOMIYA, R. Impactos Sociais e Efeitos Cumulativos decorrentes de grandes projetos de desenvolvimento: Aplicação de Redes de Impactos e Sobreposição de Mapas em estudo de caso para o Litoral Norte Paulista. Dissertação (Mestrado em Ciências da Engenharia Ambiental) - Escola de Engenharia de São Carlos, Universidade de São Paulo, São Carlos, 2014. 